\title{
HYDRAULIC BOUNDARY CONDITIONS FOR A MAJOR DISCHARGE FACILITY - THE IJSSELMEER PROJECT, THE NETHERLANDS
}

\author{
H.G. Voortman ${ }^{1}$, N. van Veen ${ }^{2}$, A. Vrijburcht ${ }^{3}$, J. Tigchelaar $^{4}$
}

The IJsselmeer (lake IJssel) in the Netherlands is a man-made lake that was formed when a $1200 \mathrm{~km}^{2}$ portion of the Wadden Sea was closed of in the 1930's. Today, the lake is vital to the water management of a major portion of the Netherlands. In view of expected climate change a major increase of the discharge capacity in the dam is currently under preparation. An extensive study was undertaken to establish hydraulic conditions for structural design. This paper describes the model that was created to establish relevant combinations of head difference and wave loads at the structure.

\section{INTRODUCTION}

The IJsselmeer (lake IJssel) in the Netherlands was formed when a $1200 \mathrm{~km}^{2}$ portion of the Wadden Sea was closed of by a $30 \mathrm{~km}$ long dam. Today, the IJsselmeer plays a vital role in the water management of a major portion of the Netherlands, including its capital, Amsterdam. Excess water from a number of low-lying areas is discharged into the lake. Furthermore, one of the principal branches of the river Rhine finds its mouth in the IJsselmeer. At low tide, discharge facilities in the closure dam discharge the water from the lake into the sea.

In view of expected climate change, sea levels are expected to rise which will reduce the capacity of the existing facilities. Therefore, the existing discharge capacity in the dam is expected to become insufficient. The Dutch Ministry of Public Works and Water Management is preparing the construction of a completely new discharge facility in the closure dam. The facility will add approximately $1000 \mathrm{~m}^{2}$ of orifice and will thus double the existing discharge capacity. By the construction of this facility, Dutch water management is expected to be sustainable at least up to the year 2100. In the course of this project, an extensive study was undertaken into the hydraulic conditions on both sides of the dam, focussed on the structural design of the new facility.

\footnotetext{
${ }^{1}$ ARCADIS Netherlands, P.O. Box 220, NL-3800 AE, Amersfoort, The Netherlands ${ }^{2}$ HKV Consultants, P.O. Box 2120, NL-8203 AC, Lelystad, The Netherlands

${ }^{3}$ Ministry of Public Works and Water Management, P.O. Box 20000, NL-3502 LA, Utrecht, The Netherlands

${ }^{4}$ Ministry of Public Works and Water Management, P.O. Box 20000, NL-3502 LA, Utrecht, The Netherlands
} 


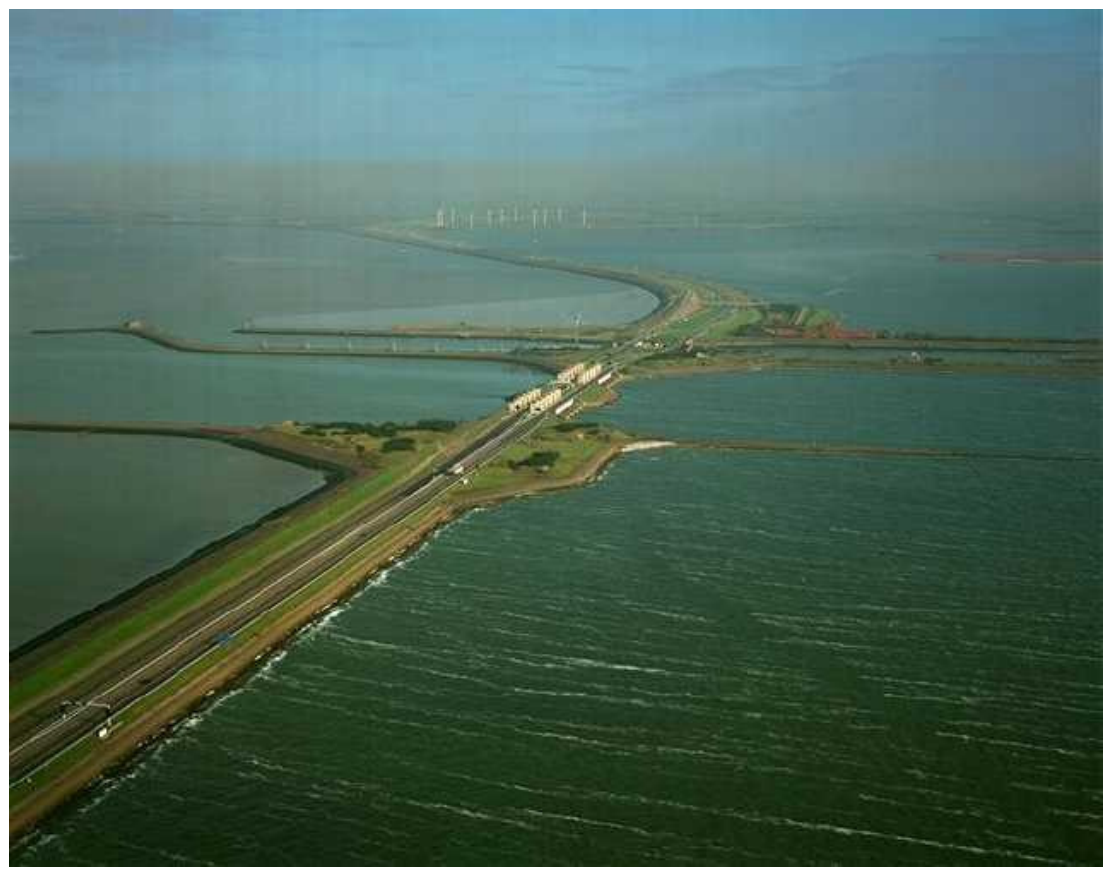

Figure 1. One of the existing discharge facilities in the closure dam. The lake is to the right and the Wadden Sea to the left

\section{FUNCTIONAL ANALYSIS AND HYDRAULIC CONDITIONS FOR DESIGN}

\section{General}

The basis for determining the type of hydraulic conditions needed for design is an understanding of the functions of the structure. To verify that a design meets with functional requirements, quantitative measures of relevant hydraulic parameters need to be established.

\section{Functional analysis of the structure}

The structure is located in an existing flood defence and should increase the discharge capacity. Therefore, the two main functions of this structure are:

- Discharging excess water into the Wadden Sea

- Preventing an increase of the water level at the IJsselmeer due to failure of the structure under extreme conditions. This would jeopardise the safety of the flood defences around the lake 
A third important function stems from the IJsselmeer being a major fresh water reserve for the Netherlands:

- Preventing an increase of the chlorine content of the water in the IJsselmeer because of the intrusion of sea water

\section{Failure modes and hydraulic conditions for design}

Derived from the functions of the structure, a number of failure modes can be established. A distinction is made between serviceability limit states and ultimate limit states. The table below provides an overview.

\begin{tabular}{|c|c|}
\hline Ultimate limit states & Serviceability limit states \\
\hline $\begin{array}{ll}\text { Main } & \text { failure modes: } \\
- & \text { Structural failure } \\
- & \text { Overtopping/overflow } \\
- & \text { Exceedance of acceptable water levels at } \\
& \text { IJsselmeer due to failed closure }\end{array}$ & $\begin{array}{l}\text { Main failure modes: } \\
-\quad \text { Insufficient discharge capacity } \\
-\quad \text { Fatigue } \\
-\quad \text { Chlorine intrusion due to failed } \\
\text { - } \quad \text { Dlosure } \\
-\quad \text { Dynamic loading of closure gates }\end{array}$ \\
\hline $\begin{array}{ll}\text { Hydraulic conditions for design: } \\
-\quad \text { Extreme wave conditions } \\
- & \text { Extreme water levels } \\
- & \text { Extreme head differences }\end{array}$ & $\begin{array}{l}\text { Hydraulic conditions for design: } \\
-\quad \text { Day-to-day wave conditions } \\
-\quad \text { Day-to-day water levels } \\
-\quad \text { Day-to-day head differences }\end{array}$ \\
\hline
\end{tabular}

The focus of this paper is on design for ultimate limit states. For design purposes, relevant combinations of wave conditions, water levels and head differences must be established.

\section{CHARACTERISTICS OF THE PROJECT LOCATION}

\section{Legal background}

The closure dam between the IJsselmeer and the Wadden Sea is part of the system of so-called "primary flood defences" of the Netherlands. This system is vital to the protection of the Netherlands against flooding.

Strict reliability requirements incorporated in Dutch law apply for these flood defences. For the project location, the flood defence should be designed for conditions with a return period of 10,000 years for wave overtopping and a return period of 1,000,000 years for structural failure. The long return periods imply that the design conditions need to be established by extrapolation from observed conditions. It is vital that this extrapolation is done by a robust method, respecting physical limits. An overview of a number of methods to establish joint statistics of hydraulic conditions is given in (Voortman 2002). Over the years, a large number of different approaches have been proposed. However, most of these methods are aimed at joint statistics of wave height and wave period only. The number of methods incorporating the water level together with the wave conditions is highly limited. Only the methods by Vrijling and Bruinsma (1980), 
Hawkes et al (2002) and Webbers et al. (2003) incorporate the water level. A model describing the combined conditions in two adjacent water bodies has not been found in literature.

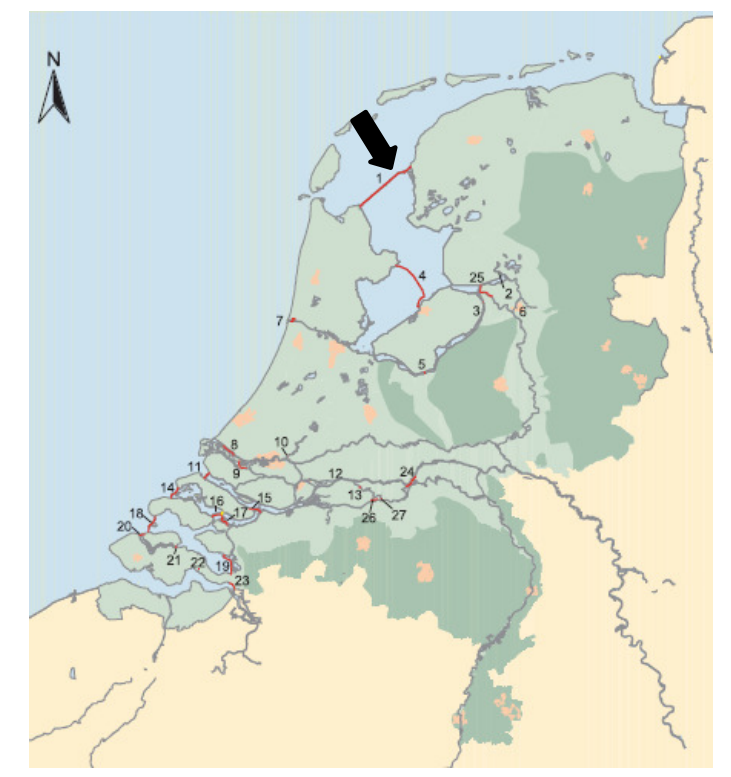

Figure 2. Part of the Dutch flood defence system. Every part of the system has a unique number. The project is located in defence number 1 , indicated by the arrow (map taken from the Dutch Flood Defence Act)

\section{Physical processes at the project location}

The project location is special from the physical point of view, since it is located between the sea and a major inland water body. Both water bodies respond to the occurring wind fields both with respect to water level (wind setup and wind setdown) and wave conditions. The conditions at the sea side are determined by the response of the North Sea and the local response of the shallow Wadden Sea to the wind. The IJsselmeer, being a major water body in itself shows its own response to the wind. A schematic overview of the physical relations is given below (inspired upon Vrijling and Bruinsma, 1980; see also Voortman, 2002). 


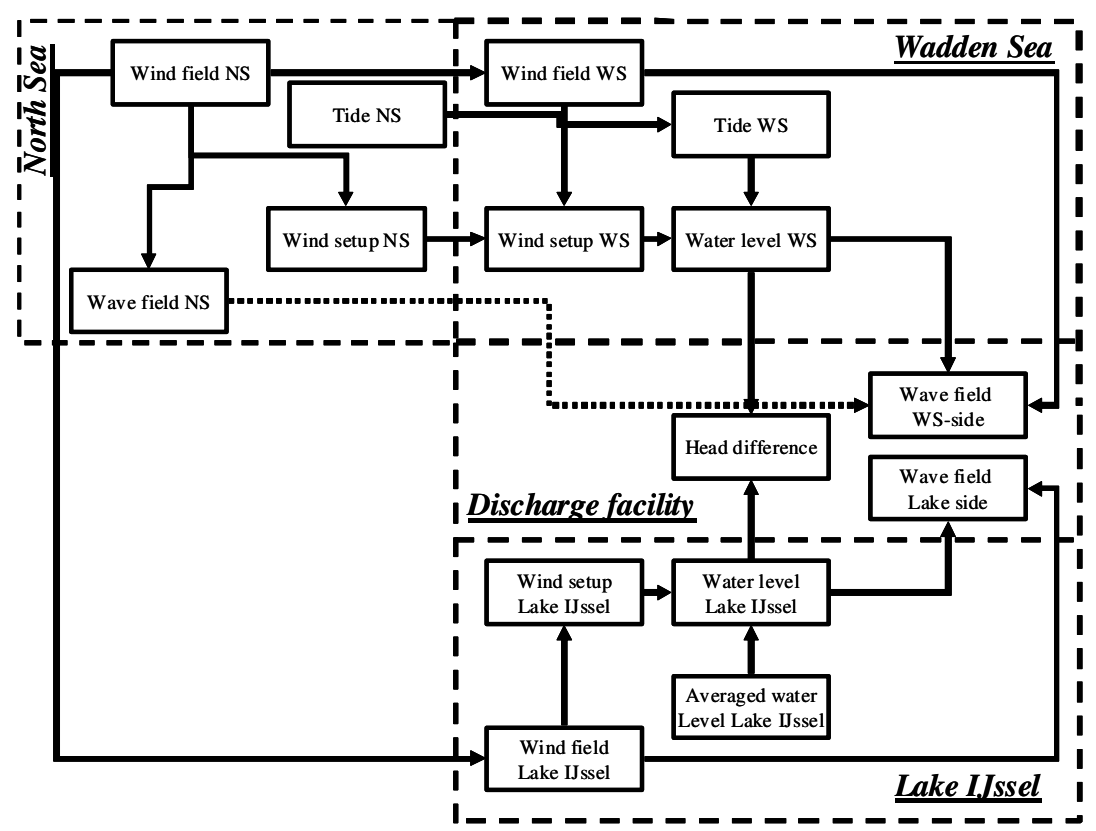

Figure 3. Schematic overview of physical relations between North Sea, Wadden Sea, IJsselmeer (denoted "Lake") and the project location

The dominating driver for the hydraulic conditions at the project location is the wind field. On the sea side, the wind drives the extremes of the water levels and drives the extreme wave conditions. The tide is a second, limited influence on the water level. The wind and the local water level together determine the wave conditions on the sea side. The wave field can be thought to consist of two main components:

- Waves generated locally in the shallow Wadden Sea

- Waves generated in the North Sea and entering the Wadden Sea through the openings between the barrier islands

In principle, both sources of wave energy contribute to the loading of the structure. In developing the model, it was uncertain whether or not North Sea waves could enter through the relatively narrow openings between the barrier islands. It was found that a limited amount of North Sea wave energy in the spectrum could lead to a serious increase in wave forces because it increases the energy in the lower frequencies of the spectrum. The wave loads are sensitive to this part of the spectrum. A separate study into the penetration of North Sea waves in the Wadden Sea was undertaken. From this study it was concluded that influence of North Sea waves at the project location could be ruled out. This conclusion was later confirmed by more extensive studies into wave penetration 
in the North Sea. More information is provided in Zijderveld and Peters (2009), Groeneweg et al (2009), van Vledder et al (2009) and Holthuijsen et al (2009).

On the lake side, the extreme conditions are dominated by the wind field. The spatially averaged water level is a reflection of the water balance of the area and is controlled by operating the discharge facilities in the dam. Therefore, the variability of this water level is very limited and is of little influence on the head differences.

The response on both sides of the dam not only depends on the wind speed, but also on the wind direction. From observation data, it was found that the response of the water level with respect to the wind direction differs for the sea and the lake. The figure below shows the response of the water levels on both sides of the dam.

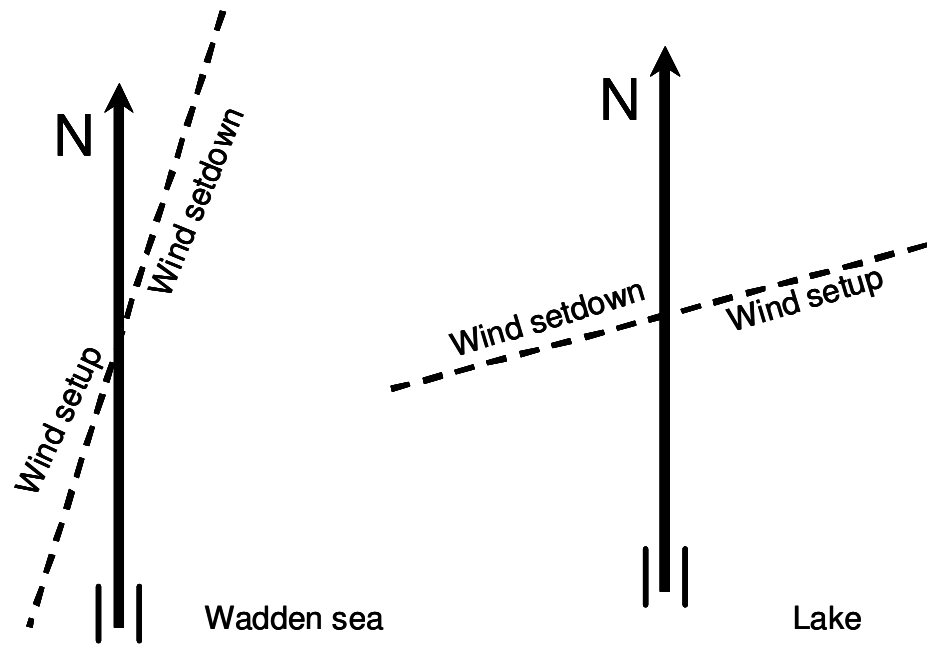

Figure 4. Response of the water level at the Wadden Sea (left panel) and the Lake (right panel) with respect to the wind direction

A second conclusion derived from data analysis is that the response on the sea side is larger than the response on the lake side, leading to the situation that head differences of the dam are dominated by the sea water level. Therefore, landward loads are expected when the wind direction is between $285^{\circ} \mathrm{N}$ and $15^{\circ} \mathrm{N}$, predominantly caused by wind setup on the sea side. Seaward loads are expected when the wind direction is between $15^{\circ} \mathrm{N}$ and $285^{\circ} \mathrm{N}$, predominantly caused by wind setdown on the sea side. 

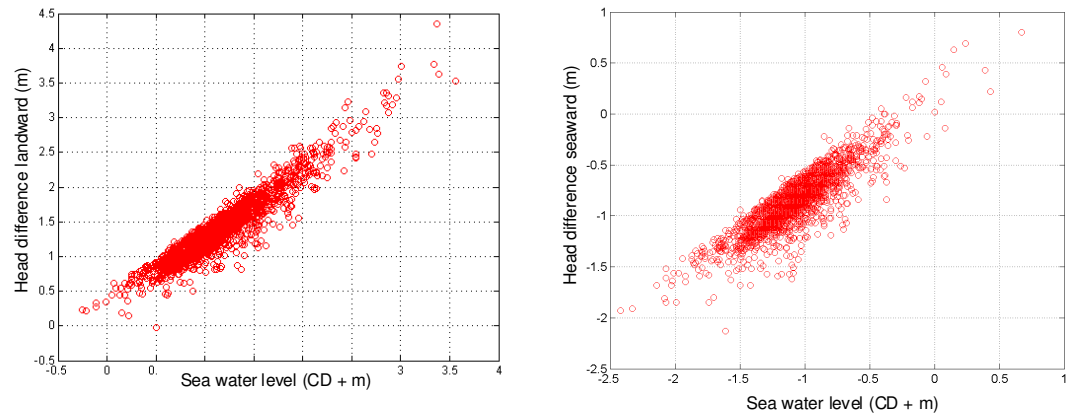

Figure 5. Observed head differences at the dam plotted as a function of the sea water level (left panel: landward loads, right panel seaward loads)

\section{THE MODEL}

\section{Basic choices}

Based on the analysis of the characteristics of the project location and a few other considerations, a basic setup of the model was established:

- The model is based on a combination of statistical analysis and parametric physical modelling. This approach is considered more robust when extrapolating to the extremes needed for design and better suited for describing the combined conditions on both sides of the dam. A joint statistical model based in physics ensures that physical limits are respected in the extrapolation process. Furthermore, establishing the relations between the conditions at the sea and at the lake on a physical basis was considered more practical in a physics-based approach

- The water level at the Wadden Sea was selected as the prime input parameter. For this parameter, the longest data range and the best established statistical basis was available

- A directional approach was adopted, where the response of the water levels and waves is derived in $15^{\circ}$ sectors

- The dependence between the water level in the Wadden Sea and the water level at the Lake is described with a parametric model, based on physics. The dominating influence of the wind was used to establish the dependence model

- Climate change was incorporated by assuming an increase of the mean sea level of $0.60 \mathrm{~m}$ until the year 2100

- Again based on the relation between the wind and the water level, the wind speeds were derived from the water level

- The wave conditions are established on the basis of parametric models, using the aforementioned wind speed as input

- The dependence models are calibrated on the available data 
- Validation of the model is performed by verifying that the model reproduces the marginal distributions of the modelled variables

\section{Results of the model, head differences}

Model calibration has been performed by calibrating the physical relations to the available data. An example is shown below.
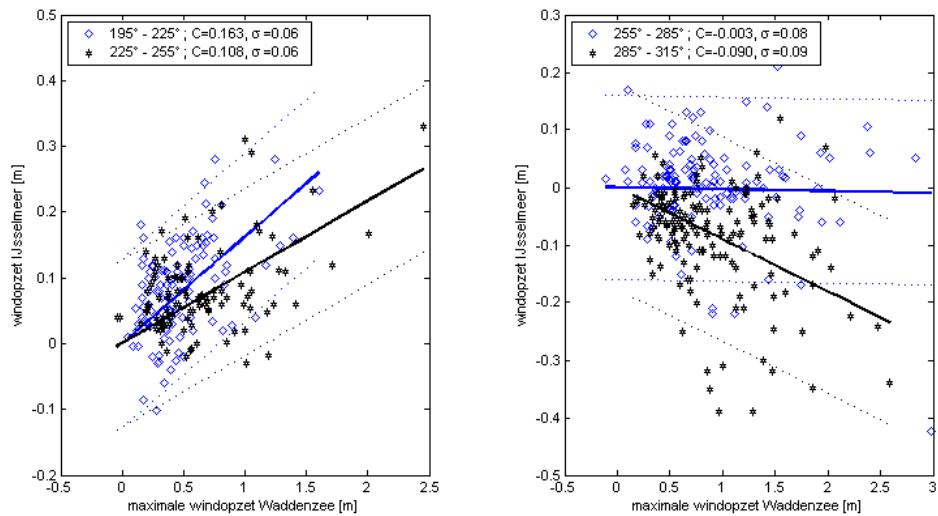

Figure 6. Example of calibration of parts of the model. Relation of wind setup and setdown on both sides of the dam

Since the available data is limited, proper validation against a separate data set could not be performed. The model was validated by inspecting the marginal probability distributions that emerged from the model. The performance of the model for the head difference is satisfactory (see figures below).

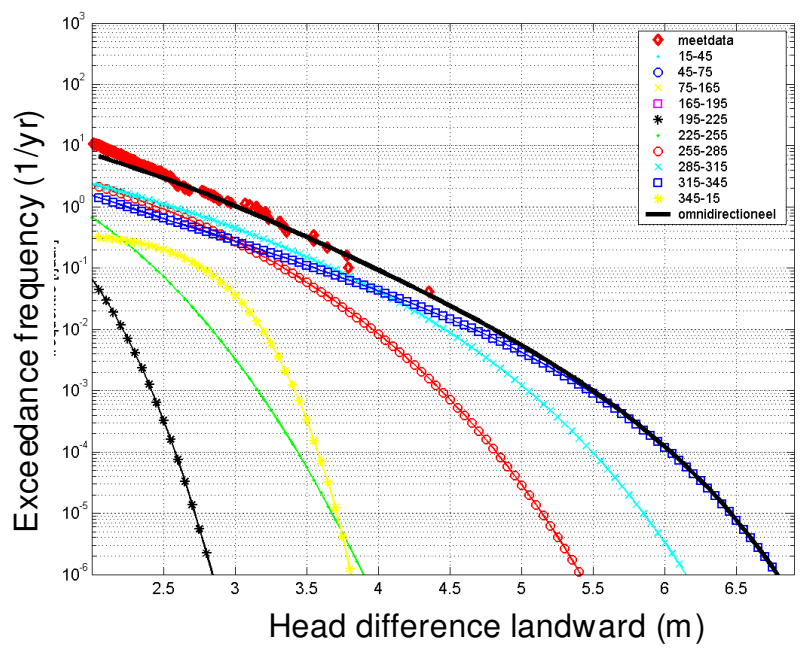

Figure 7. Marginal distribution of the landward head difference as resulting from the model in comparison to the available data 


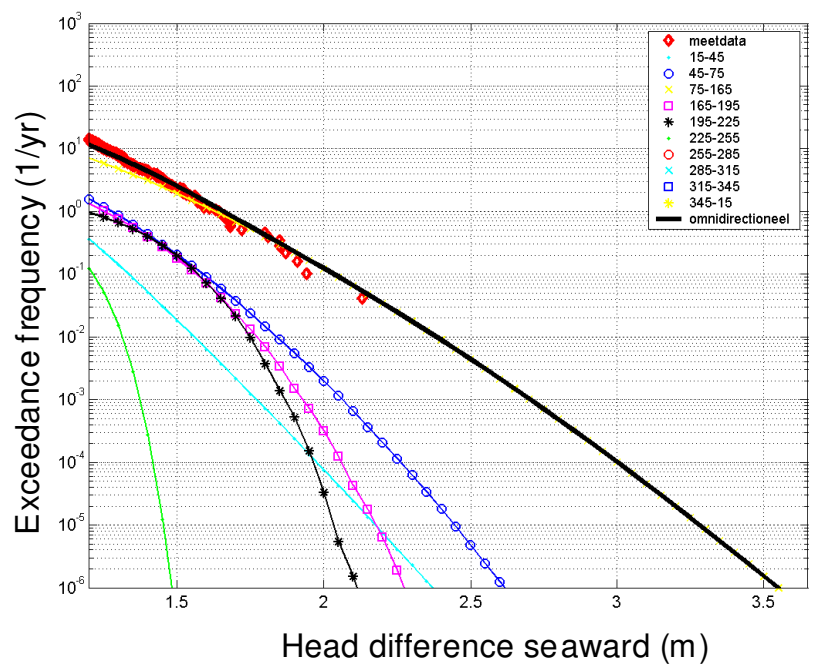

Figure 8. Marginal distribution of the seaward head difference as resulting from the model in comparison to the available data

It is emphasized that the marginal distribution shown above is not the result of direct fitting of a statistical distribution to the data, but is derived from the calibrated physical/statistical model.

\section{Results of the model, wave conditions sea side}

Observation data on the sea side of the dam is very limited. The data of an observation period of only 15 months is available. This data was used for calibration purposes but the results are treated with some care (see figures below). As an additional source of validation, the conditions were compared to the conditions used for the safety assessment of the dam itself. 


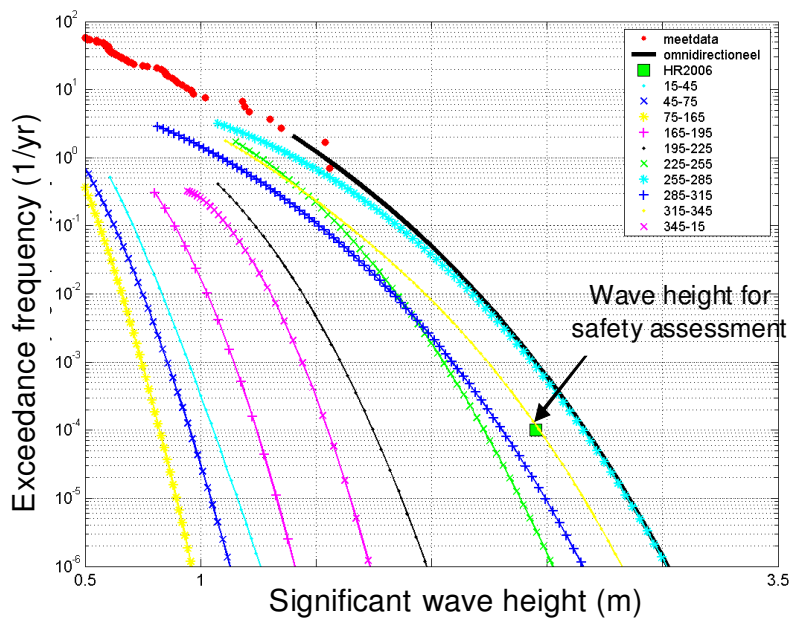

Figure 9. Marginal distribution of the significant wave height on the sea side. The basis for validation is weak. The derived conditions for design are slightly more conservative than the currently used wave height for safety assessment

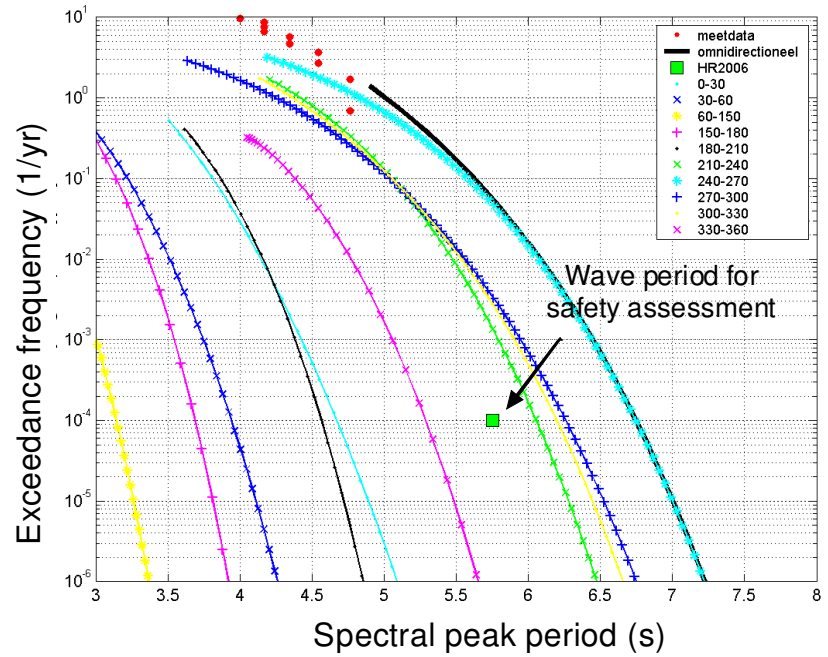

Figure 10. Marginal distribution of the spectral peak period on the sea side. The basis for validation is weak. The derived conditions for design are more conservative than the currently used wave period for safety assessment

Within the course of the project, additional studies were performed into the wave conditions in the Wadden Sea to verify whether more extreme conditions were physically possible. Ultimately, the model result was accepted for design. It 
was concluded that the conditions were on the verge of the physically possible and therefore sufficiently robust for design.

\section{Results of the model, wave conditions lake side}

On the lake side, calibrated parametric models derived in an earlier study were used (Dutch Ministry of Public Works and Water Management, 1999). The used study was aimed at establishing the assessment conditions for the flood defences around the lake and was therefore considered sufficiently reliable for the purposes of this study. Wave data for the purposes of calibration or validation was lacking completely. The marginal distributions derived from the model are shown below.

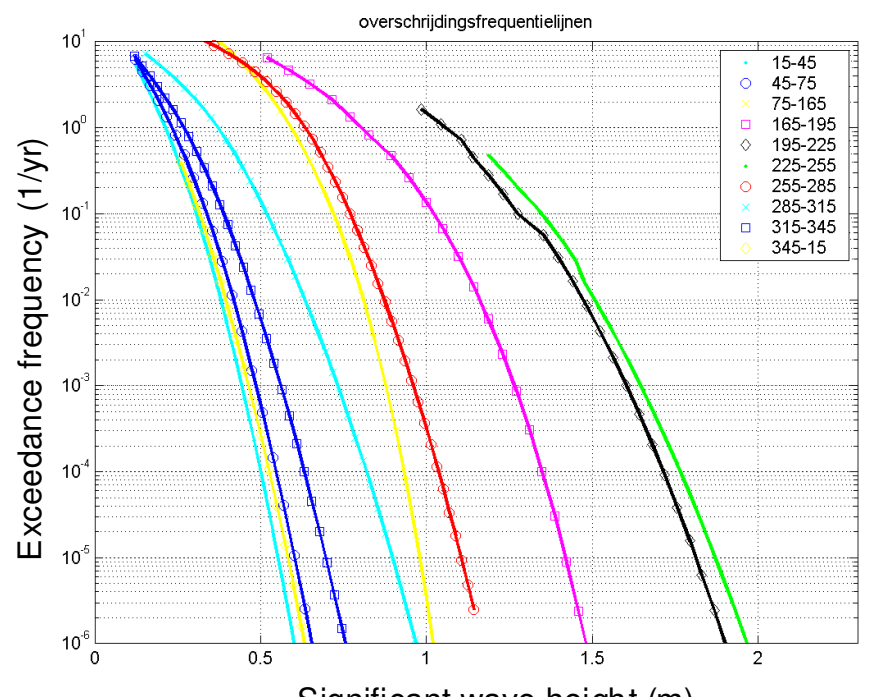

Significant wave height $(\mathrm{m})$

Figure 11. Marginal distribution of the significant wave height on the lake side. Data for validation is lacking 


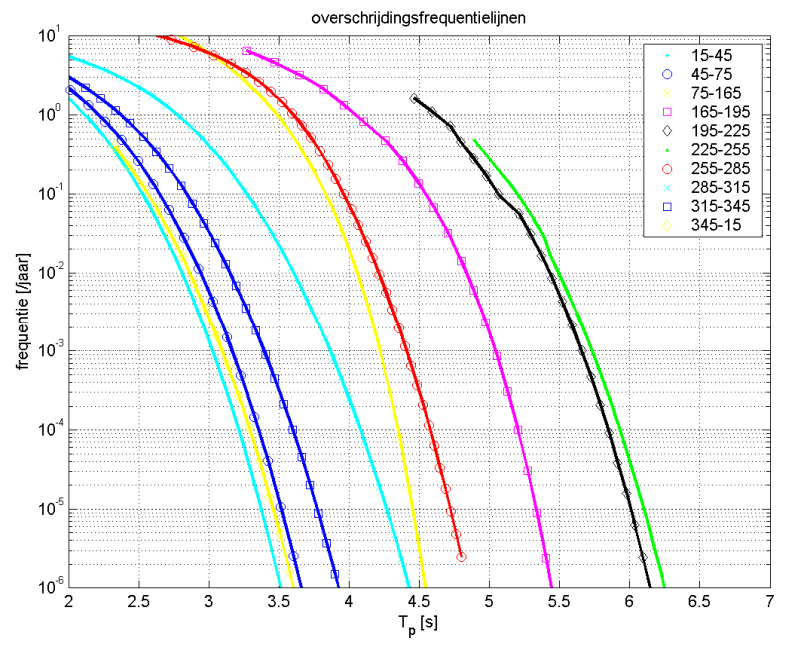

Figure 12. Marginal distribution of the spectral peak period on the lake side. Data for validation is lacking

\section{CONCLUSIONS}

The design and construction of a major discharge facility in the dam separating the Dutch "IJsselmeer" from the Wadden Sea requires a valid set of hydraulic conditions for design. Because of the nature of the project location, loads are predominantly wind-driven. The response of the North Sea, the Wadden Sea and the lake together determine the loading of the structure.

An extensive study into the hydraulic conditions for design was undertaken. The available data was used to establish a model for the joint statistics of wave conditions at both sides of the structure and the head loads over the structure. Calibration and validation of the model was performed by using the limited available data and by performing separate studies into the physics of the project location.

The end result was a set of hydraulic conditions that is considered sufficiently robust and reliable for application in the design of the structure.

\section{REFERENCES}

Dutch Ministry of Public Works and Water Management 1999, Backgrounds of Hydraulic Loads on flood defences in the IJsselmeer (in Dutch), Series of ten reports 
Groeneweg, J; Van der Westhuysen, A; Van Vledder, G; Jacobse, S; Van Dongeren, A. 2009, Wave modelling in tidal inlet, performance of SWAN in the Wadden Sea, Proceedings of the $31^{\text {st }}$ International Conference on Coastal Engineering

Hawkes, P.J; Gouldy, P.B; Tawn, J.A; Owen, M.W. 2002, The joint probability of waves and water levels in coastal engineering, Journal of Hydraulic Research, IAHR. Volume 40 - pg. 241-251

Holthuijsen, L.H; Zijlema, M; Van Slingerland, P. 2009, Wave physics in a tidal inlet, Proceedings of the $31^{\text {st }}$ International Conference on Coastal Engineering, ASCE

Van Vledder, G; Groeneweg, J; Van Dongeren, A (2009), Numerical and physical aspects of wave modelling in a tidal inlet, Proceedings of the $31^{\text {st }}$ International Conference on Coastal Engineering, ASCE

Voortman, H.G. 2003, Risk-based optimisation of large-scale flood defence systems, Phd-thesis Delft University of Technology

Vrijling, J.K. and Bruinsma, J. 1980, Hydraulic boundary conditions, Symposium on Hydraulic Aspects of Coastal Structures

Webbers, P.B; Voortman, H.G; Van Gelder, P.H.A.J.M; Vrijling, J.K. 2003, Multi-variate statistics of hydraulic boundary conditions for the Rotterdam harbour extension, Proceedings of the $28^{\text {th }}$ International Conference on Coastal Engineering, ASCE

Zijderveld, A; Peters, H (2009), Field measurement program in the Dutch Wadden Sea, Proceedings of the $31^{\text {st }}$ International Conference on Coastal Engineering, ASCE 
KEYWORDS - ICCE 2008

HYDRAULIC BOUNDARY CONDITIONS FOR A MAJOR DISCHARGE

FACILITY - THE IJSSELMEER PROJECT, THE NETHERLANDS

H.G. Voortman

N. van Veen

A. Vrijburcht

J. Tigchelaar

Abstract number 681 (paper 397 at the conference)

Coastal structures

Wave conditions

Statistics

Joint probability modelling

Water levels

Head differences

Structural design

Flood defence 